\title{
4-Aminoacetophenone Intercalated CoAl Layered Double Hydroxides: Synthesis, Characterization and Adsorptive Removal of Cd(II) Ions from Water Samples
}

\author{
Abdul Rafay Bhatti ${ }^{1}$, Ali Nawaz Siyal ${ }^{1}$, Qadeer Khan Panhwar ${ }^{1}$, \\ Abdul Majid Channa ${ }^{1}$, Muhammad Hassan Agheem², \\ Adnan Ahmed ${ }^{3}$ and Muhammad Yar Khuhawar ${ }^{1}$ \\ ${ }^{1}$ Institute of Chemistry, University of Sindh, Jamshoro 76080, Pakistan. \\ ${ }^{2}$ Centre for Pure \& Applied Geology, Sindh, Jamshoro 76080, Pakistan. \\ ${ }^{3}$ Centre for Environmental Science, University of Sindh, Jamshoro 76080, Pakistan. \\ *Corresponding Author Email: alinsiyal@ usindh.edu.pk \\ Received 28 August 2020, Revised 25 March 2021, Accepted 26 March 2021
}

\begin{abstract}
In the present study, $\mathrm{CoAl}-\mathrm{NO}_{3}$ Layered Double Hydroxides $\left(\mathrm{CoAl}-\mathrm{NO}_{3}-\mathrm{LDH}\right)$ was synthesized and an enolate anion of 4-Aminoacetophenone (AAP) was intercalated into LDH following the reconstruction approach. The CoAl- $\mathrm{NO}_{3}-\mathrm{LDH}$ and CoAl-AAP-LDH were characterized by Fourier-Transform infrared (FT-IR) spectroscopy, X-ray diffraction (XRD), scanning electron microscope (SEM) and energy dispersive X-ray (EDX) analyses. CoAl-AAP-LDH worked well for adsorption of $\mathrm{Cd}(\mathrm{II})$ ions from aqueous samples at optimum $\mathrm{pH} \mathrm{7}$, adsorbent dosage $25 \mathrm{mg}$, concentration of $\mathrm{Cd}$ (II) ions $25 \mathrm{mg} \mathrm{L}^{-1}$ and shaking time $20 \mathrm{~min}$ at $25{ }^{\circ} \mathrm{C}$. Different isotherms such as Langmuir, Freundlich and Dubinin-Radushkevich (D-R) isotherms fitted well to adsorption data with correlation coefficient $\left(\mathrm{R}^{2}\right)$ of $0.998,0.982$ and 0.992 , respectively. Monolayered $\left(\mathrm{Q}_{\mathrm{m}}\right)$ and multi-layered $\left(\mathrm{K}_{\mathrm{F}}\right)$ capacities of CoAl-AAP-LDH for adsorption of $\mathrm{Cd}(\mathrm{II})$ ions were calculated and found to be 34.40 and $19.44 \mathrm{mg} \mathrm{g}^{-1}$, respectively. Sorption energy was calculated and found to be $9.13 \mathrm{~kJ} \mathrm{~mol}^{-1}$, indicating chemisorption or ion exchange sorption mechanism. The method worked well for the adsorption of Cd(II) ions from wastewater samples.
\end{abstract}

Keywords: Layered Double Hydroxides, Enolate ions, Intercalation, Adsorption, Cd(II) ions, Isotherms

\section{Introduction}

Layered double hydroxides (LDH) are two dimensional ionic lamellar compounds, also known as hydrotalcite-like or compounds. They are composed of divalent and trivalent metal ions hydroxides sheets/layers possessing a positive charge. The positive charge on sheets/layers is due to the substitution of some portion of $\mathrm{M}^{2+}$ cation of the brucite-like layer with $\mathrm{M}^{3+}[1,2]$. These sheets are sandwiched, intercalated with anions for balancing the positive charge. LDH is represented by general formula $\left[\mathrm{M}_{1-\mathrm{x}}{ }^{2+} \mathrm{M}_{\mathrm{x}}{ }^{3+}(\mathrm{OH})_{2}\right]^{\mathrm{x}+}\left(\mathrm{A}_{\mathrm{x} / \mathrm{n}}^{\mathrm{n}-}\right)^{\mathrm{x}-}$ . $\mathrm{yH}_{2} \mathrm{O}$, where $\mathrm{M}^{2+}$ is divalent cations such as $\mathrm{Mg}, \mathrm{Co}, \mathrm{Zn}, \mathrm{Ni}, \mathrm{Cd}, \mathrm{Mn}$, etc., $\mathrm{M}^{3+}$ is trivalent cations such as $\mathrm{Al}, \mathrm{Fe}, \mathrm{Cr}, \mathrm{Ga}, \mathrm{Bi}$, etc. in the brucite-like layers and $\mathrm{A}^{\mathrm{n}-}$ is intercalated anions possessing $\mathrm{n}$ charge such as $\mathrm{CO}_{3}{ }^{2-}$, $\mathrm{NO}_{3}{ }^{-}, \mathrm{OH}$ and $\mathrm{Cl}^{-}, \mathrm{x}$ is equal to the molar ratio of $\mathrm{M}^{2+} /\left(\mathrm{M}^{2+}+\mathrm{M}^{3+}\right)$, $\mathrm{n}$ can be in the range of $0.2-0.33$, and $\mathrm{y}$ is the number of water molecules [3]. Various LDHs have been synthesized by coprecipitation of mixed metal 
cations $\left(\mathrm{M}^{2+}+\mathrm{M}^{3+}\right)$ solution using $\mathrm{NaOH}$ base and urea as a source of a base at different conditions such as composition ratio of $\mathrm{M}^{2+}+$ $\mathrm{M}^{3+}$ solution, temperature and aging period. The anions can be deintercalated or converted to mixed oxides by calcination. Taking the advantage of memory effect, various LDHs have recon prepared mixed oxides by reconstruction approach followed by hydrolysis [4]. Due to anion exchangeability, compositional flexibility, biocompatibility, LDHs have been attracted for various applications as catalysts or catalyst precursors, flame retardants, stabilizers for polymers, and electroactive, photoactive materials, anion exchangers, adsorbent, etc. [5]. The selectivity and efficiency of the LDH adsorbent can be improved by acid activation, surface modification and thermal treatment, and intercalation of inorganic and organic anions [6]. Intercalated anions are exchangeable with suitable inorganic and organic anions, due to which LDHs have been attracted as selective and efficient adsorbents [7]. Various organic anions such as ethylenediaminetetraacetate (EDTA) [8,9], mercaptocarboxylic acid in to MgAl [10], aurintricarboxylic acid [11], amino acids [2,12], Chromotropic acid [13], Schiff base [14], diethylenetriaminepentaacetic acid [15], diethylenetriaminepentaacetate, meso-2,3-dimercaptosuccinate [16], citrate, malate and tartrate [17] have been interacted into LDH for the adsorption metal ions. To the best of our knowledge, there is no report on enolate intercalation into LDH. In the present study, enolate of 4Aminoacetophenone (AAP) will be intercalated into CoAl-LDH for $\mathrm{Cd}(\mathrm{II})$ ions adsorption from aqueous samples.

\section{Materials and Methods}

Perkin Elmer flame atomic absorption spectrometer (AAnalyst 800, USA) with hollow cathode lamp was employed for Cd(II) ions determination. Thermo Scientific FT-IR spectrometer (Nicolet iS10, UK) was used to record the FT-IR spectrum. The material was characterized by powder X-ray diffraction (XRD) by Diffractometer (Bruker D8 advance, German) employing $\mathrm{Cu}-\mathrm{K} \alpha$ $(\lambda=1.54056 \AA)$. Samples were scanned in the range of $2 \theta=5.0^{\circ}-80^{\circ}$ at $0.01^{\circ}$ intervals at room temperature. A scanning electron microscope (JSM-6490LV, JEOL, Japan) was used for scanning SEM images. Bruker $\mathrm{X}$ Flash $4010133 \mathrm{ev}$ (made in Germany) using $\mathrm{Cu}-\mathrm{K} \alpha(\lambda=1.5406 \AA)$ radiation was used for EDX analysis. Shaker (Model No.1-4000, Germany) was used for shaking purpose. For $\mathrm{pH}$ measurements, a $\mathrm{pH}$ meter (inoLab $\mathrm{pH}$ 720 , Germany) was used. Double distilled water and analytical reagent grade chemicals were used throughout the research. $\mathrm{Co}\left(\mathrm{NO}_{3}\right)_{2} \cdot 6 \mathrm{H}_{2} \mathrm{O}, \quad \mathrm{Al}\left(\mathrm{NO}_{3}\right)_{3} \cdot 9 \mathrm{H}_{2} \mathrm{O}$ were purchased from Sigma-Aldrich, China. $\mathrm{CH}_{3} \mathrm{COOH} / \mathrm{CH}_{3} \mathrm{COONa}, \quad \mathrm{H}_{3} \mathrm{PO}_{4} / \mathrm{NaH}_{2} \mathrm{PO}_{4}$ and $\mathrm{NH}_{4} \mathrm{OH} / \mathrm{NH}_{4} \mathrm{Cl}$ were used as buffer solutions for maintaining the desired $\mathrm{pH}$.

\section{Preparation of CoAl- $\mathrm{NO}_{3} \mathrm{LDH}$}

CoAl-NO $\mathrm{NOH}_{3}$ was prepared, followed by co-precipitation method $[9,18,19]$. Experimentally, an aqueous $0.1 \mathrm{~mol}$ $\mathrm{L}^{-1} \mathrm{NaOH}$ solution was prepared and added dropwise to $500 \mathrm{~mL}$ of an aqueous solution containing $0.03 \mathrm{~mol}$ of $\mathrm{Co}\left(\mathrm{NO}_{3}\right)_{2} \cdot 6 \mathrm{H}_{2} \mathrm{O}$ and $0.01 \mathrm{~mol}$ of $\mathrm{Al}\left(\mathrm{NO}_{3}\right)_{3} \cdot 9 \mathrm{H}_{2} \mathrm{O}$ with stirring continuously until $\mathrm{pH}$ reached 10 . The mixture was stirred continuously for $24 \mathrm{~h}$ at room temperature and the resulting slurry was aged at room temperature for $124 \mathrm{~h}$ and centrifuged. The final precipitated product $\left(\mathrm{CoAl}-\mathrm{NO}_{3}-\mathrm{LDH}\right)$ was filtered and washed with water until filtrate turned to neutral and oven-dried at $60^{\circ} \mathrm{C}$ for $24 \mathrm{~h}$.

\section{Intercalation of AAP into CoAl-NO $\mathrm{O}_{3}-\mathrm{LDH}$}

Figure 1 shows the scheme for intercalation of enolate ions into $\mathrm{CoAl}-\mathrm{NO}_{3}-$ $\mathrm{LDH}$ followed by the reconstruction approach 
[20-22]. Experimentally, nitrate ions were deintercalated from $\mathrm{CoAl}-\mathrm{NO}_{3}-\mathrm{LDH}$ by calcination at $400{ }^{\circ} \mathrm{C}$ in the furnace. Thereafter, $1.5 \mathrm{~g}$ of AAP was tautomerized by dissolving in $100 \mathrm{~mL}$ of methanol, containing $0.01 \mathrm{~g}$ of $\mathrm{NaOH}$. Thereafter, $1.0 \mathrm{~g}$ of calcined material was dispersed in the solution and refluxed for $4 \mathrm{~h}$. The final product (CoAlAAP-LDH) was filtered, washed with water until filtrate turned neutral and oven-dried at $60{ }^{\circ} \mathrm{C}$ for $24 \mathrm{~h}$.

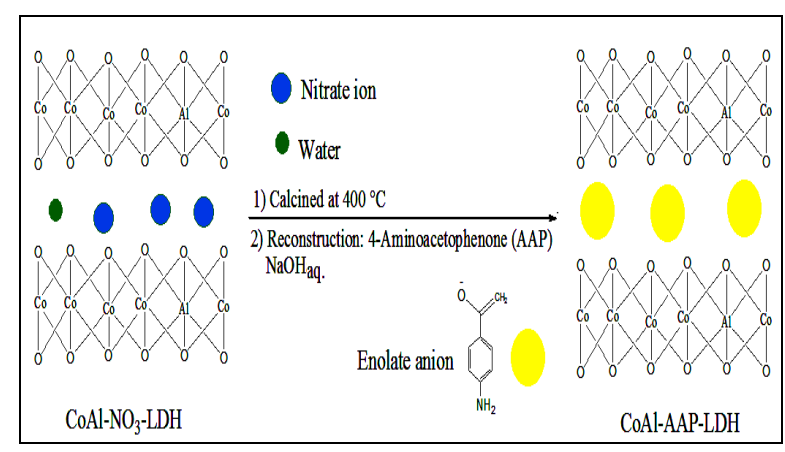

Figure 1. Scheme for intercalation of enolate ions into $\mathrm{CoAl}-\mathrm{NO}_{3}$ LDH

\section{Adsorption Experiment}

The efficiency of CoAl-AAP-LDH adsorbent for the adsorption of $\mathrm{Cd}(\mathrm{II})$ ions was tested by the batch procedure. Experimentally, $25 \mathrm{mg}$ of CoAl-AAP-LDH adsorbent was placed into $100 \mathrm{~mL}$ bottle containing $20 \mathrm{~mL}$ of $25 \mathrm{mg} \mathrm{L}^{-1} \mathrm{Cd}$ (II) ions of pH 7.0 and shaken at $120 \mathrm{rpm}$ for $20 \mathrm{~min}$ at room temperature. The mixture was filtered and filtrated was subjected to FAAS for determination of residual $\mathrm{Cd}(\mathrm{II})$ ions. The adsorption of $\mathrm{Cd}(\mathrm{II})$ ions was $95.5 \%$, as calculated by equation 1 .

$\operatorname{Adsorption}(\%)=\frac{\left[(\mathrm{C}]_{\mathrm{i}}-\mathrm{F}_{\mathrm{f}}\right)}{\mathrm{C}_{1}} 100$

Where $C_{i}$ and $C_{f}$ are the initial and final concentrations of $\mathrm{Cd}(\mathrm{II})$ ions, respectively.
Results and Discussions

\section{Characterization}

FT-IR spectroscopy

Figure 2 shows FT-IR spectra of CoAl-NO $-\mathrm{LDH}$ (a), calcined CoAl-LDH (b) and CoAl-AAP-LDH (c). Peaks in spectrum-a at $3377.69 \mathrm{~cm}^{-1}$ correspond to stretching vibrations of $\mathrm{O}-\mathrm{H}$ bonds of $\mathrm{LDH}$ sheet and intercalated water [23], peak at $1646.56 \mathrm{~cm}^{-1}$ attributed to bending vibration of $\mathrm{O}-\mathrm{H}$ bond of intercalated water [9], peak at $1346.49 \mathrm{~cm}^{-1}$ corresponds to stretching vibration of $\mathrm{N}=\mathrm{O}$ bond of intercalated nitrate ions [24, 25] and peak at $844.48 \mathrm{~cm}^{-1}$ attributed to stretching vibrations of M-O (Co$\mathrm{O}$ and Al-O) bond of metal hydroxides, respectively [22]. This spectral information indicated the intercalation of nitrate ions and water into the CoAl-LDH. The broad weak peak in spectrum-b at $3377.69 \mathrm{~cm}^{-1}$ attributed to stretching vibrations of $\mathrm{O}-\mathrm{H}$ bonds of $\mathrm{LDH}$ sheet and intercalated residual water, weak peak at $1646.56 \mathrm{~cm}^{-1}$ attributed to the bending vibration of $\mathrm{O}-\mathrm{H}$ bond of water, which was probably captured from environment. The peak at $844.48 \mathrm{~cm}^{-1}$ attributed to the stretching vibrations of $\mathrm{M}-\mathrm{O}$ bonds of metal hydroxides. The absence of a signal at $1346.49 \mathrm{~cm}^{-1}$ confirmed the deintercalation of nitrate ions. The broad weak peak in spectrum-c at $3288.06 \mathrm{~cm}^{-1}$ attributed to stretching vibrations of $\mathrm{O}-\mathrm{H}$ bonds of LDH sheet and intercalated residual water and weak peak at 1646.38 $\mathrm{cm}^{-1}$ attributed to the bending vibration of $\mathrm{O}-\mathrm{H}$ bond of residual water. The additional characteristic peaks in spectrum-c at 1556.5 , 1442.49 and $1442.49 \mathrm{~cm}^{-1}$ attributed to the stretching vibrations of $\mathrm{C}=\mathrm{C}$ bonds of enolate ions of AAP. Peak at $844.48 \mathrm{~cm}^{-1}$ correspond to $\mathrm{M}-\mathrm{O}$ bonds of metal hydroxides, which indicated the formation of CoAl-AAP-LDH. 


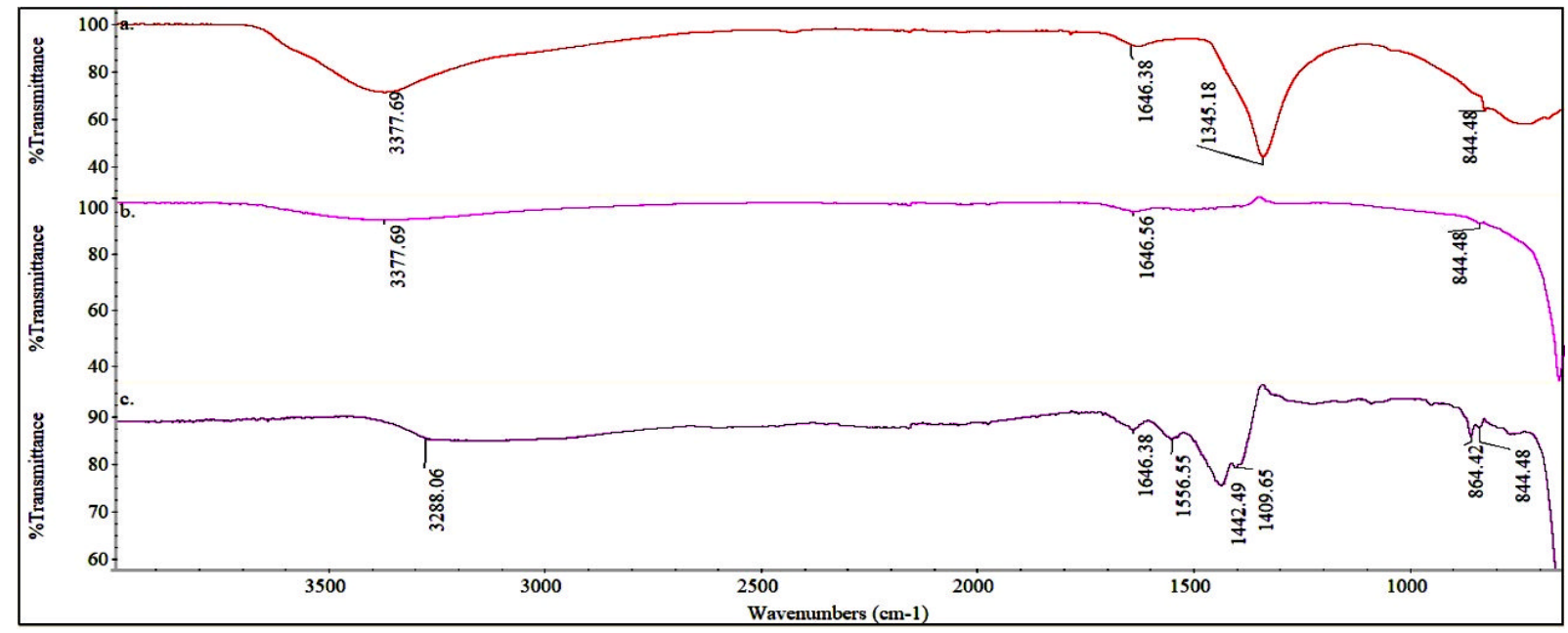

Figure 2. FT-IR spectra: CoAl-NO 3 -LDH (a), calcined CoAl-LDH (b) and CoAl-AAP-LDH (c)

$X R D$

Fig. 3 shows the powder XRD pattern of CoAl-NO $\mathrm{N}_{3}$-LDH (a) and CuAl-AAP-LDH (b). The characteristic diffraction peaks in XRD pattern (a) at $2 \theta$ values $11.57^{\circ}, 23.53^{\circ}$, $34.42^{\circ}, 60.257^{\circ}$ and $61.609^{\circ}$ correspond to (003) and (006), (012), (110) and (113) planes $(h k l)$ of hexagonal $\mathrm{CoAl}-\mathrm{NO}_{3}-\mathrm{LDH}$ phase, respectively, which confirmed the formation of hydrotalcite-like structured $\mathrm{CoAl}-\mathrm{NO}_{3}-$ LDH [26]. According to Bragg's law ( $d=$ $\mathrm{n} \lambda / 2 \operatorname{Sin} \theta$, where $\lambda$ is the wavelength of $\mathrm{X}$-rays (for $\mathrm{Cu} \mathrm{K} \alpha, \lambda=1.54056 \AA$ ) and $n=1$ (order of diffraction) and $\theta$ is the position of peaks in radian) [24], the $\mathrm{d}_{006}$ (basal spacing) in CoAL$\mathrm{NO}_{3}-\mathrm{LDH}$ was found to be $0.76 \mathrm{~nm}$, which indicated the intercalation of water molecules and nitrate anions between hydrotalcite-like layers. Using the Debye Scherrer equation [27], the average crystallite size of $\mathrm{CoA}-\mathrm{NO}_{3}-$ LDH was calculated and found to be 199.04 $\mathrm{nm}$. The characteristic diffraction peaks in XRD pattern (b) at $2 \theta$ values $11.38^{\circ}, 22.85^{\circ}$, $34.42^{\circ}, 60.36^{\circ}$ and $61.69^{\circ}$ correspond to $(003)$ and (006), (012), (110) and (113) planes of hexagonal CoAl-AAP-LDH phase, respectively, which confirmed the reconstruction of hydrotalcite-like layers [2022] and $\mathrm{d}_{006}$ was increased to $0.78 \mathrm{~nm}$, which indicated the intercalation of enolate anions of AAP between hydrotalcite-like layers. The broadness in the peaks is due to a decrease in crystalline size.

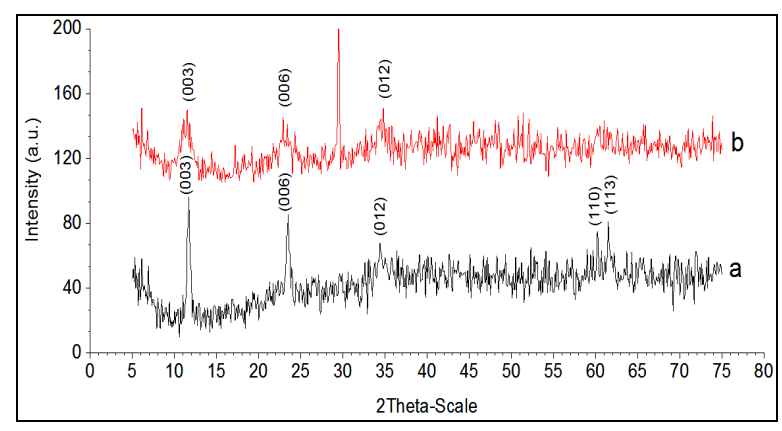

Figure 3. XRD patterns: $\mathrm{CoAl}_{-} \mathrm{NO}_{3}-\mathrm{LDH}$ (a) and CuAl-AAPLDH (b)

\section{SEM analysis}

Fig. 4 shows SEM Images of CoAl$\mathrm{NO}_{3}$-LDH (a), calcined LDH (b) and CoAlAAP-LDH (c). By comparing images a and b, the characteristic change in morphologies can be seen, which indicated deintercalation of nitrate ions and formation of mixed CoAl oxides, occurred by calcination at $400{ }^{\circ} \mathrm{C}$. By comparing images $\mathrm{b}$ and $\mathrm{c}$, the characteristic changes in morphologies can be seen, which confirmed the reconstruction of LDH by intercalation of AAP i.e., CoAl-AAP-LDH. 

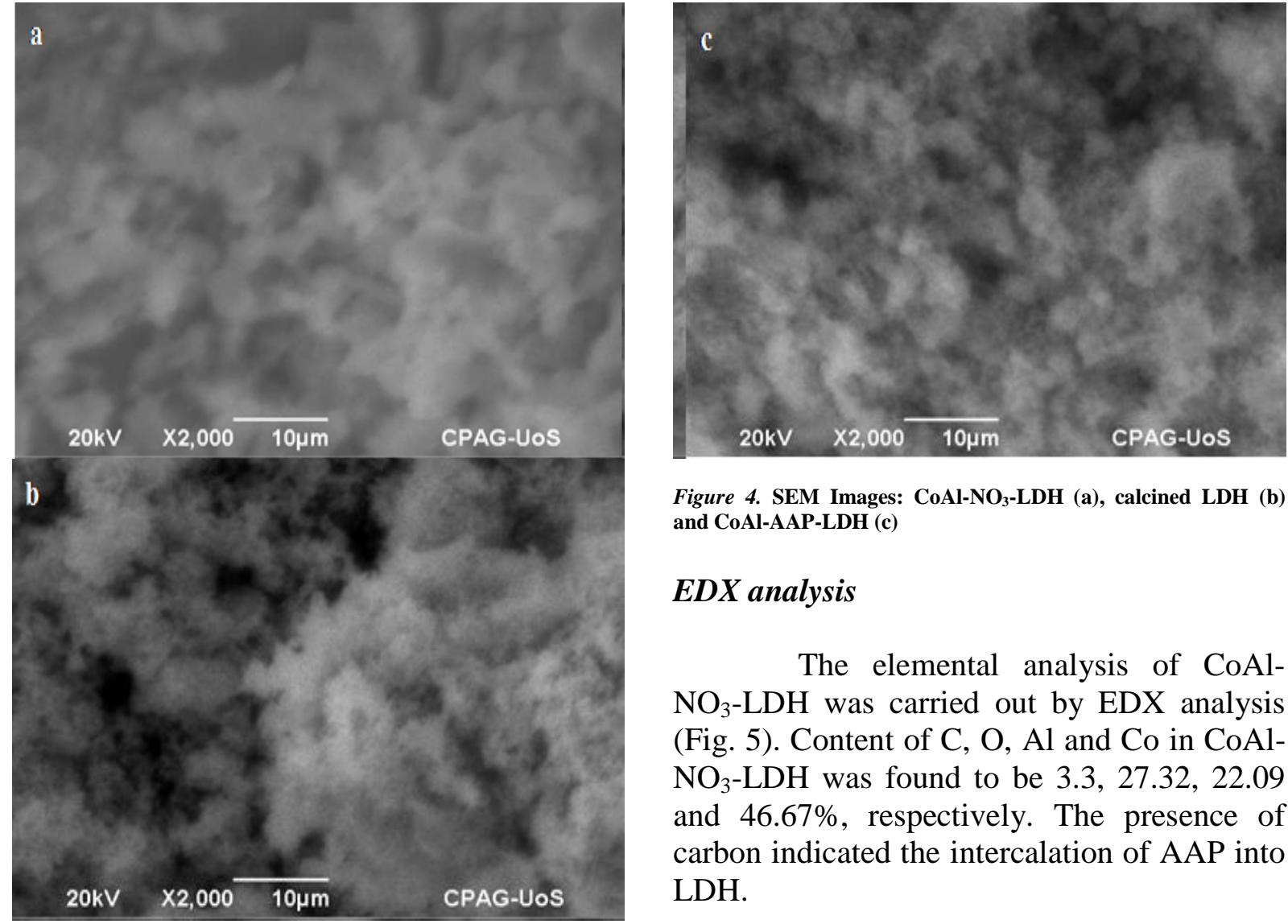

Figure 4. SEM Images: CoAl-NO${ }_{3}-\mathrm{LDH}$ (a), calcined LDH (b) and CoAl-AAP-LDH (c)

\section{EDX analysis}

The elemental analysis of CoAl$\mathrm{NO}_{3}$-LDH was carried out by EDX analysis (Fig. 5). Content of $\mathrm{C}, \mathrm{O}, \mathrm{Al}$ and $\mathrm{Co}$ in $\mathrm{CoAl}-$ $\mathrm{NO}_{3}$ - $\mathrm{LDH}$ was found to be 3.3, 27.32, 22.09 and $46.67 \%$, respectively. The presence of carbon indicated the intercalation of AAP into LDH.

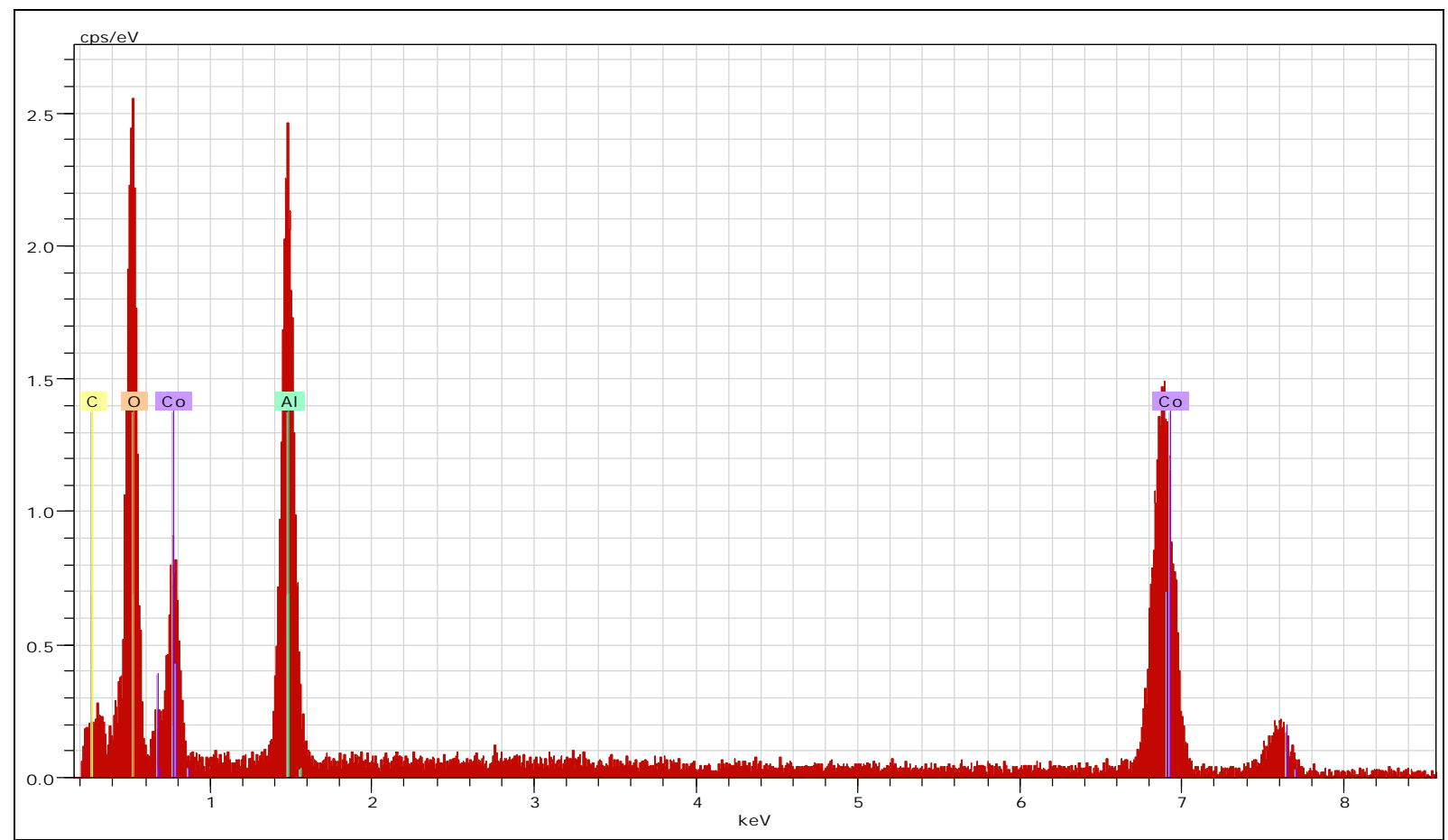

Figure 5. EDX of CoAl-AAP-LDH 
Optimization

Effect of $\mathrm{pH}$

The effect of $\mathrm{pH}$ 2-9 on adsorption of $\mathrm{Cd}$ (II) ions onto CoAL-AAP-LDH was examined. Cd(II) ions were adsorbed $94.0 \%$ at $\mathrm{pH} 7$, as shown in Fig. 6a. The adsorption trend can be justified as in an acidic medium, $\mathrm{Cd}^{2+}$ ions and $\mathrm{H}^{+}$ions were competing for interacting with CoAL-AAP-LDH adsorbent, While, with increasing of $\mathrm{pH} 4-7, \mathrm{H}^{+}$ions were decreasing and $\mathrm{Cd}(\mathrm{II})$ ions were interacted dominantly, resulted increase in adsorption. Further increasing of $\mathrm{pH}$ 8-9, adsorption was increased, which is due to the formation of $\mathrm{Cd}(\mathrm{OH})_{2}$ precipitates $[28,29]$. Therefore, $\mathrm{pH} 7$ was chosen as the optimum $\mathrm{pH}$ for further experiments.

\section{Effect of shaking time}

Adsorption depends on the contact time between adsorbent and adsorbate. Practically, the effect of contact time 5-50 min on $\mathrm{Cd}$ (II) ions adsorption onto CoAL-AAPLDH adsorbent was studied. Adsorption of $\mathrm{Cd}(\mathrm{II})$ ions was increased with the increase of contact time and became maximum at $20 \mathrm{~min}$ (Fig. 6b ). The adsorption was slightly decreased with further increasing of shaking time due to desorption. Therefore, $20 \mathrm{~min}$ was chosen as the optimum shaking time for further experiments.

\section{Effect of adsorbent dosage}

Different dosage 5-50 mg of CoAlAAP-LDH adsorbent for the adsorption of $\mathrm{Cd}(\mathrm{II})$ ions was tested. The adsorption was increased with increasing of adsorbent dosage and reached to maximum at $30 \mathrm{mg}$ as depicted in Fig. 6c. Adsorption was slightly decreased and then became almost constant with further increase of the dosage $30-50 \mathrm{mg}$. Therefore, $25 \mathrm{mg}$ of the adsorbent was chosen as the best dose for further adsorption experiments.

\section{Effect of concentration}

The concentration of adsorbate is an important parameter that shows the uptake efficiency of adsorbent. Thus, the effect of initial concentration ranging $5-50 \mathrm{mg} \mathrm{L}^{-1}$ of Cd(II) ions was examined as shown in Fig. 6d. The adsorption was increased with increasing of concentration ranging $5-25 \mathrm{mg} \mathrm{L}^{-1}$ of $\mathrm{Cd}$ (II) ions and slightly decreased with further increasing of concentration due to fully saturation at the surface of CoAL-AAP-LDH. Therefore, the optimum concentration of $\mathrm{Cd}(\mathrm{II})$ ions was chosen as $25 \mathrm{mg} \mathrm{L}^{1}$ for further experiments.
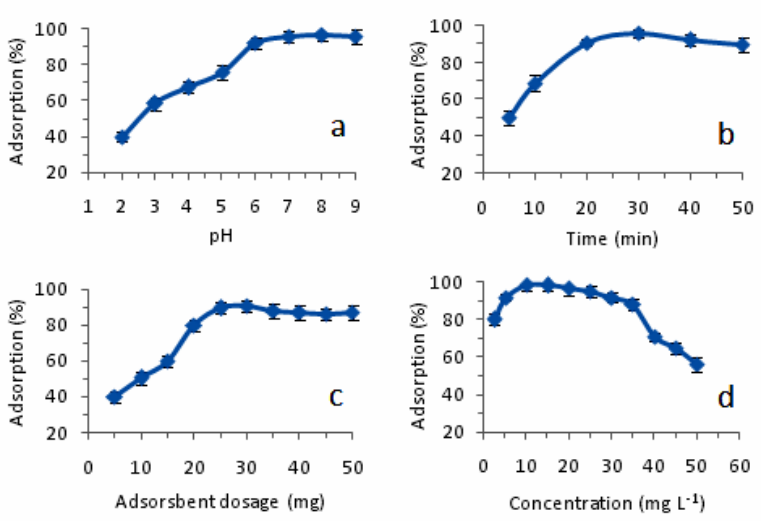

Figure 6. Optimization: Effect of pH (a), shaking time (b), dosage (c) and concentration (d)

\section{Effect of matrix ions}

The performance of adsorbent for adsorption of $\mathrm{Cd}(\mathrm{II})$ ions was assessed in the presence of $500 \mathrm{mg} \mathrm{L}^{-1}$ various common ions such as $\mathrm{Na}^{+}, \mathrm{K}^{+}, \mathrm{Mg}^{2+}, \mathrm{Ca}^{2+}, \mathrm{Cl}^{-}, \mathrm{F}^{-}, \mathrm{HCO}_{3}^{-}$, $\mathrm{CO}_{3}{ }^{2-}, \quad \mathrm{SO}_{4}{ }^{2-}, \quad \mathrm{NO}_{3}{ }^{-}$and $\mathrm{CH}_{3} \mathrm{COO}^{-}$. Therefore, adsorbent worked well and $\geq 90.5 \%$ of $\mathrm{Cd}(\mathrm{II})$ ions was adsorbed onto the adsorbent.

\section{Equilibrium Studies}

Equilibrium study for the adsorption of $\mathrm{Cd}(\mathrm{II})$ ions onto $\mathrm{LDH}$ was carried at room temperature by varying the concentration of 
$\mathrm{Cd}(\mathrm{II})$ ions in the range of $5-50 \mathrm{mg} \mathrm{L}^{-1}$ while other parameters were fixed at their optimum levels i.e., adsorbent dosage $=25 \mathrm{mg}, \mathrm{pH}=$ 7.0 and shaking time $=20 \mathrm{~min}$. Different isotherms such as Langmuir isotherm, D-R isotherm and Freundlich isotherms were plotted for analyzing the adsorption data.

\section{Langmuir isotherm}

Langmuir isotherm assumes that the surface of adsorbent is homogeneous, possessing equally distributed active sites for adsorption. All the active sites have equal affinity for adsorption with constant adsorption energy. Monolayered sorption occurs onto the surface of adsorbent without interaction between adsorbed molecules or metal ions. A linear form of Langmuir isotherm is represented by equation 2 .

$$
\frac{\mathrm{C}_{\mathrm{e}}}{\mathrm{C}_{\text {ads. }}}=\frac{1}{\mathrm{Q}_{\mathrm{m}}} \mathrm{C}_{\mathrm{e}}+\frac{1}{\mathrm{Q}_{\mathrm{m}} \mathrm{b}_{\mathrm{L}}}
$$

Where $\mathrm{C}_{\mathrm{e}}\left(\mathrm{mg} \mathrm{L}^{-1}\right)$ is the concentration of $\mathrm{Cd}(\mathrm{II})$ ions in the aqueous phase at equilibrium, $\mathrm{C}_{\mathrm{ads}}$. $\left(\mathrm{mg} \mathrm{g}^{-1}\right)$ is the amount of $\mathrm{Cd}(\mathrm{II})$ ions adsorbed onto the surface of adsorbent. Where $\mathrm{Q}_{\mathrm{m}}\left(\mathrm{mg} / \mathrm{g}^{-1}\right)$ is the maximum adsorption capacity (mono layered) of the adsorbent and $b_{L}\left(\mathrm{~L} \mathrm{mg}^{-1}\right)$ is Langmuir constant, related to the affinity of active sites for adsorption and binding energy. The characteristic of Langmuir isotherm is the separation factor $\left(\mathrm{R}_{\mathrm{L}}\right)$ which can be calculated by equation 3 . The values of $R_{L}$ suggest the feasibility of adsorption. The adsorption may be irreversible $\left(R_{L}=0\right)$, unfavorable $\left(R_{L}>1\right)$, and favorable $\left(0<R_{L}<1\right)$ [30].

$$
\mathrm{R}_{\mathrm{L}}=\frac{1}{1+\left(\mathrm{B}_{\mathrm{L}} \mathrm{C}_{1}\right)}
$$

The Langmuir isotherm was plotted (Fig. 7) as $\mathrm{C}_{\mathrm{e}} / \mathrm{C}_{\mathrm{ads}}$ versus $\mathrm{C}_{\mathrm{e}}$ and fitted well to adsorption data with $\mathrm{y}=0.029 \mathrm{x}+0.020, \mathrm{R}^{2}=$ 0.998 . The monolayered sorption capacity of CoAl-AAP-LDH adsorbent for Cd(II) ions was calculated and found to be 34.40 $\mathrm{mg} \mathrm{g}^{-1}$. Values of $\mathrm{R}_{\mathrm{L}}$ were calculated and found to be in the range of 0.064-0.02, suggested that adsorption of $\mathrm{Cd}(\mathrm{II})$ ions onto CoAl-AAP-LDH adsorbent was favorable.

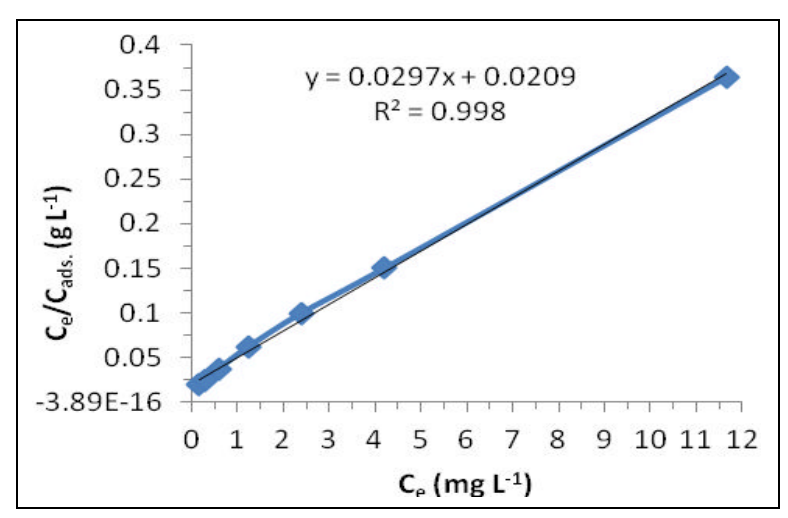

Figure 7. Langmuir isotherm

\section{Freundlich isotherm}

Freundlich isotherm describes multilayered adsorption onto the surface of adsorbent by assuming that the surface of adsorbent is heterogeneous, possessing different (unequal) active sites. The sites possess a different affinity for adsorption with different sorption energy. The linear form of Freundlich isotherm is represented by equation 4 [31].

$\log c=C_{a d s}=\frac{1}{n} \log C_{e}+\log K_{F}$

Where $\mathrm{K}_{\mathrm{F}}$ is the Freundlich constant and related to the maximum adsorption capacity of metal ions $\left(\mathrm{mg} \mathrm{g}^{-1}\right)$ and $1 / \mathrm{n}$ is a dimensionless constant which illustrates the adsorption intensity. The Freundlich isotherm was plotted (Fig. 8) as $\log C_{\text {ads. }}$ versus $\log C_{e}$ and fitted well to adsorption data with $\mathrm{y}=$ $0.225 \mathrm{x}+1.288, \mathrm{R}^{2}=0.981$. Multi-layered sorption capacity of adsorbent for Cd(II) ions was calculated and found to be $19.44 \mathrm{mg} \mathrm{g}^{-1}$ with $1 / \mathrm{n}$ of 0.225 , which suggested that active 
sites are heterogeneously distributed onto the surface of adsorbent.

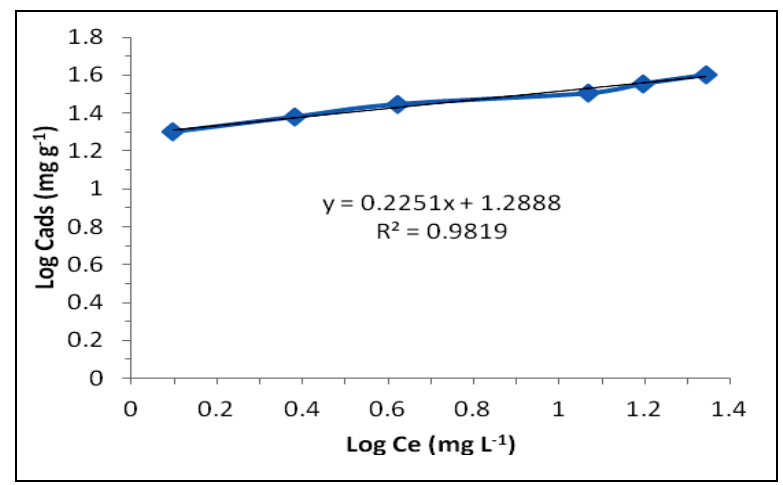

Figure 8. Freundlich isotherm

\section{D-R isotherm}

The D-R isotherm assumes no homogeneous surface of adsorbent. It is useful to estimate the characteristics of porosity of the adsorbent and energy of adsorption. A linear form of D-R isotherm is represented by equation 5 .

$\mathrm{InC}_{\mathrm{ads}}=\ln \mathrm{k}_{\mathrm{D}-\mathrm{R}}-\beta_{\varepsilon}^{2}$

Where $\beta$ is the slope of D-R isotherm, $\mathrm{K}_{\mathrm{D}-\mathrm{R}}$ is $\mathrm{D}-\mathrm{R}$ constant and $\varepsilon$ is polanyi potential, which can be calculated by equation 6.

$$
\varepsilon=\mathrm{RT} \operatorname{lm}\left(1+\frac{1}{\mathrm{C}_{\mathrm{e}}}\right)
$$

Where $\mathrm{R}$ (general gas constant) = $8.314 \mathrm{~J} \mathrm{~mol}^{-1} \mathrm{~K}^{-1}$ and $\mathrm{T}$ is temperature $=298 \mathrm{~K}$ and $\mathrm{E}$ is Free energy of adsorption can be calculated by equation 7 . Value of $E$ predicts the mechanism of adsorption, which can be physisorption if $\mathrm{E}<8 \quad \mathrm{~kJ}^{-1} \quad \mathrm{~mol}^{-1}$ or chemisorption if E>8-16 kJ mol${ }^{-1}$ [30]. The D$\mathrm{R}$ isotherm was plotted (Fig. 9) as $\ln \mathrm{C}_{\mathrm{ads}}$. versus $\epsilon^{2}$ and fitted well with $\mathrm{y}=-0.006 \mathrm{x}$ $0.9742, \mathrm{R}^{2}=0.9917$. E was calculated and found to be $9.13 \mathrm{~kJ} \mathrm{~mol}^{-1}$, suggested chemisorptions or/and ion exchange mechanism of for adsorption of $\mathrm{Cd}(\mathrm{II})$ ions onto CoAl-AAP-LDH.

$$
\mathrm{E}=\frac{1}{\sqrt{-2 \beta}}
$$

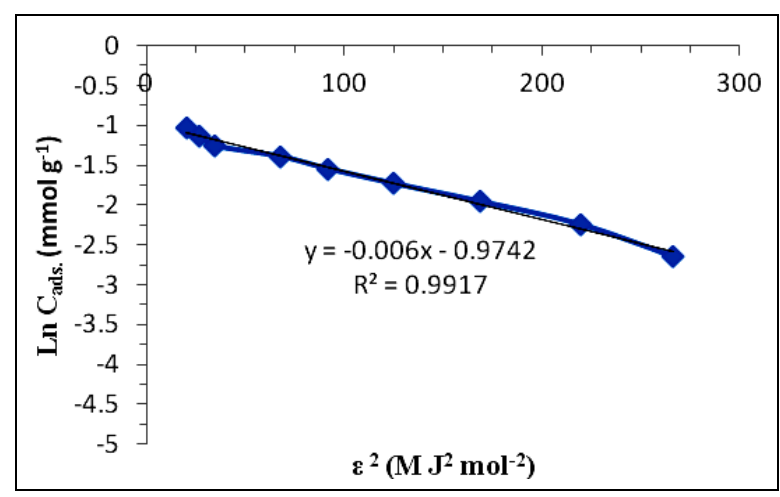

Figure 9. D-R isotherm

\section{Application of the method}

The repeatability of the developed method was checked by applying on spiked water samples. Removal of $\mathrm{Cd}(\mathrm{II})$ ions achieved was $>94.0 \%$ as shown in Table 1 . The results showed that $\mathrm{Cd}(\mathrm{II})$ ions were removed from spiked water samples.

Table 1. Application of method: Removal of $\mathrm{Cd}(\mathrm{II})$ ions from spiked wastewater samples.

\begin{tabular}{lccc}
\hline Samples & Added $\left(\mathbf{m g ~ L}^{-1}\right)$ & Found $\left(\mathbf{m g ~ L}^{-1}\right)$ & $\begin{array}{c}\text { Removal } \\
(\%) \pm \text { RSD }\end{array}$ \\
\hline S-I & 0.0 & ND & - \\
& 5.0 & 4.5 & $90.0 \pm 4.0$ \\
& 10 & 9.5 & $95.0 \pm 3.0$ \\
& 20 & 18.6 & $93.0 \pm 3.0$ \\
\hline S-II & 0.0 & ND & - \\
& 5.0 & 4.1 & $82.0 \pm 4.0$ \\
& 10 & 9.2 & $92.0 \pm 3.5$ \\
& 20 & 17.9 & $89.5 \pm 4.0$ \\
\hline
\end{tabular}

ND: Not detected; S-I: Tap water sample collected from research laboratory, Institute of Chemistry, University of Sindh Jamshoro, Pakistan; S-II Wastewater sample collection from Combined Effluent Treatment Plant in Korangi, Karachi, Pakistan 


\section{Comparison with Reported Methods}

Various LDH adsorbents have methods synthesized for adsorption of $\mathrm{Cd}$ (II) ions from aqueous samples. The capacity of CoAl-AAP-LDH is comparatively better than reported adsorbents, as shown in Table 2.

Table 2. Comparative capacities of LDHs adsorbents for adsorption of $\mathrm{Cd}(\mathrm{II})$ ions.

\begin{tabular}{lccc}
\hline Adsorbents & $\mathbf{Q}_{\mathbf{m}}\left(\mathbf{m g ~ g}^{-\mathbf{1}}\right)$ & $\mathbf{p H}$ & Ref. \\
\hline $\mathrm{MgAl}-\mathrm{Humate}$ & 39.34 & 5.0 & {$[32]$} \\
$\mathrm{MgAl}-\mathrm{Cl}$ & 52.38 & 5.0 & {$[33]$} \\
$\mathrm{Fe}_{3} \mathrm{O}_{4} / \mathrm{MgAl}-\mathrm{LDH}$ & 45.64 & 4.0 & {$[34]$} \\
$\mathrm{MgAl}-\mathrm{LDH}$ & 61.38 & 9.0 & {$[34]$} \\
$\mathrm{NiAl-LDH}$ & 10.70 & 7.0 & {$[35]$} \\
$\begin{array}{l}\text { Carbon quantum dots/ZnAl- } \\
\text { LDH }\end{array}$ & 12.60 & 6.0 & {$[36]$} \\
NiMo-LDH & 53.60 & 5.5 & {$[37]$} \\
$\begin{array}{l}\text { Maifanite/MgAl-LDHs } \\
\text { ZnAl-EDT-LDH/ Poly(vinyl }\end{array}$ & 3.77 & 7.0 & {$[38]$} \\
$\begin{array}{l}\text { alcohol) } \\
\text { MgMn-LDH }\end{array}$ & 9.54 & 5.0 & {$[39]$} \\
Kiwi-biocha/MgFe LDH & 633.44 & 5.0 & {$[40]$} \\
$\begin{array}{l}\text { Heat treated humic acid/MgAl- } \\
\text { LDH } \\
\text { CoAl-AAP-LDH }\end{array}$ & 155.28 & 7.0 & {$[42]$} \\
\hline
\end{tabular}

\section{Conclusion}

CoAl- $\mathrm{NO}_{3}-\mathrm{LDH}$ was synthesized by co-precipitation method. The precipitated product was aged for a period of 120 for enhancing the crystalline size. The formation of layered material was confirmed from XRD pattern by showing an intense peak at $2 \theta=$ $11.57^{\circ}$ and $23.53^{\circ}$. The basal spacing $\left(\mathrm{d}_{006}\right)$ in CoAL-NO ${ }_{3}-\mathrm{LDH}$ was found to be $0.76 \mathrm{~nm}$, which indicated the intercalation of nitrate anions and the average crystallite size of CoA$\mathrm{NO}_{3}-\mathrm{LDH}$ was calculated and found to be $199.04 \mathrm{~nm}$. The nitrate anions were deintercalated by calcined at $400{ }^{\circ} \mathrm{C}$, and enolate ions were intercalated into $\mathrm{LDH}$ by reconstruction approached. Different isotherms such as Langmuir, Freundlich and $\mathrm{D}-\mathrm{R}$ isotherms fitted well to adsorption data with $\mathrm{R}^{2}$ of $0.992-0.982 . \mathrm{Q}_{\mathrm{m}}$ and $\mathrm{K}_{\mathrm{f}}$ of CoAlAAP-LDH adsorbent for adsorption $\mathrm{Cd}(\mathrm{II})$ ions were calculated and found to be 34.40 and $19.44 \mathrm{mg} \mathrm{g}^{-1}$, respectively. Sorption energy was found to be $9.13 \mathrm{~kJ} \mathrm{~mol}^{-1}$, which indicated that $\mathrm{Cd}(\mathrm{II})$ ions was adsorbed onto the CoAl-AAP-LDH adsorbent by chemisorption or and ion exchange mechanism. The CoAl-AAP-LDH adsorbent has high efficiency for $\mathrm{Cd}(\mathrm{II})$ ions. The Adsorbent was recycled 20 times with a significant declining its performance.

\section{Acknowledgment}

The authors would like to thank Professor Dr. Saima Qayoom Memon for her scientific guidance.

\section{Conflict of Interest}

The authors declare that there is no conflict of interest.

\section{References}

1. H. Shu, Z. Guan-Nan, Z. Chao, W. T. Weng, X. Yong-Yao and L. Tianxi, ACS Appl. Mater. Interf., 4 (2012) 2242. doi.org/10.1021/am300247x.

2. T. Hibino, Chem. Mater., 16 (2004) 5482.

doi.org/10.1021/cm048842a.

3. P. Tang, F. Deng, Y. Feng and D. Li, Ind. Eng. Chem. Res., 51 (2012) 10542. doi.org/10.1021/ie300645b.

4. X. Qiu, K. Sasaki, S. Xu and J. Zhao, Langmuir, 35 (2019) 6267.

doi.org/10.1021/acs.langmuir.8b04196.

5. Y. Yang, X. Zhao, Y. Zhu and F. Zhang, Chem. Mater., 24 (2011) 81.

doi.org/10.1021/cm201936b. 
6. M. Zubair, M. D aud G. McKay, F. Shehzad and M. A. Al-Harthi, Appl. Clay Sci., 143 (2017) 279. doi.org/10.1016/j.clay.2017.04.002.

7. M. Rosset, L. W. Sfreddo, O. W. PerezLopez and L. A. Féris, J. Environ. Chem. Eng., 8 (2020) 103991. doi.org/10.1016/j.jece.2020.103991.

8. K. A. Tarasov, D. O. Hare and V. P. Isupov, Inorg. Chem., 42 (2003) 1919. doi.org/10.1021/ic0203926.

9. M. R. Perez, I. Pavlovic, C. Barriga, J. Cornejo, M. C. Hermosín and M. A. Ulibarri, Appl. Clay Sci., 32 (2006) 245. doi.org/10.1016/j.clay.2006.01.008.

10. H. Nakayama, S. Hirami and M. Tsuhako, J. Colloid. Interf. Sci., 315 (2007) 177. doi.org/10.1016/i.jcis.2007.06.036.

11. H. Zhu, Y. Feng, P. Tang, G. Cui, D. G. Evans, D. Li and $\mathrm{X}$. Duan, Ind. Eng. Chem. Res., 50 (2011) 13299. doi.org/10.1021/ie2016366.

12. S. Aisawa, S. Takahashi, W. Ogasawara, Y. Umetsu and E. Narita, J. Solid State Chem., 162 (2001) 52. doi.org/10.1006/jssc.2001.9340.

13. Y. Chen and S. Yu-Fei, Ind. Eng. Chem. Res., 52 (2013) 4436. doi.org/10.1021/ie400108t.

14. N. Senda, I. Fujiwara and Y. Murakami, Appl. Clay Sci., 183 (2019) 105310. doi.org/10.1016/j.clay.2019.105310.

15. X. Liang, W. Hou, Y. Xu, G. Sun, L. Wang, Y. Sun and X. Qin, Colloids Surf. A, $\quad 366 \quad$ (2010) 50. doi.org/10.1016/j.colsurfa.2010.05.012.

16. I. Pavlovic, M. R. Perez, C. Barriga and M. A. Ulibarri, Appl. Clay Sci., 43 (2009) 125. doi.org/10.1016/j.clay.2008.07.020.

17. T. Kameda, H. Takeuchi and T. Yoshioka, Sep. Purif. Technol., 62 (2008) 330. doi.org/10.1016/j.seppur.2008.02.001.
18. S. V. Krishna and G. Pugazhenthi, J. Exp. Nanosci., 8 (2013) 19. doi.org/10.1080/17458080.2011.551894.

19. K. Suresh, R. V. Kumar, R. Boro, M. Kumar and G. Pugazhenthi, Mater. Today: Proceedings, 5 (2018) 1359. doi.org/10.1016/j.matpr.2017.11.222.

20. T. Hibino and A. Tsunashima, Chem. Mater., 10 (1998) 4055. doi.org/10.1021/cm980478q.

21. R. P. Bontchev, S. Liu, J. L. Krumhansl, J. Voigt and T. M. Nenoff, Chem. Mater., 15 (2003) 3669. doi.org/10.1021/cm034231r.

22. H. Nakayama, N. Wada and M. Tsuhako, Int. J. Pharm., 269 (2004) 469. doi.org/10.1016/j.ijpharm.2003.09.043.

23. F. R. Costa, A. Leuteritz, U. Wagenknecht, D. Jehnichen, L. Häußler and G. Heinrich, Appl. Clay Sci., 38 (2008) 153. doi.org/10.1016/j.clay.2007.03.006.

24. W. Li, A. Liu, H. Tian and D. Wang, Colloid. Interf. Sci. Commun., 24 (2018) 18. doi.org/10.1016/j.colcom.2018.03.003.

25. L. Mingsheng, X. Shun, G. Qingyang, D. Zuoxing, L. Qinglong and Z. Zhijun, Colloid. Interf. Sci., 538 (2019) 440. doi.org/10.1016/j.jcis.2018.12.006.

26. W. Hong, J. Wang, L. Niu, J. Sun, P. Gong and S. Yang, J. Alloys Compd., 608 (2014) 297. doi.org/10.1016/j.jallcom.2014.04.131.

27. P. F. Fato, L. Da-Wei, Z. Li-Jun, Q. Kaipei and L. Yi-Tao, ACS Omega, 4 (2019) 7543. doi.org/10.1021/acsomega.9b00731.

28. I. D. Smiciklas, S. K. Milonjić, P. Pfendt and S. Raicevic, Sep. Purif., 18 (2000) 185. doi.org/10.1016/S1383-5866(99)00066-0.

29. S. E. A. S. El-Deen, S. I. Moussa, Z. A. Mekawy, M. K. K. Shehata, S. A. Sadeek and H. H. Someda, Radiochim. Acta, 105 (2017) 43. 
doi.org/10.1515/ract-2016-2624.

30. S. Q. Memon, S. M. Hasany, M. I. Bhanger, M. Y. Khuhawar, J. Colloid Interf. Sci., 291 (2005) 84.

doi.org/10.1016/j.jcis.2005.04.112.

31. D. Kundu, S. K. Mondal and T. Banerjee, J. Chem. Eng. Data, 64 (2019) 2601.

doi.org/10.1021/acs.jced.9b00088.

32. M. A. Gonzalez, I. Pavlovic, R. RojasDelgado and C. Barriga, Chem. Eng. J., 254 (2014) 605.

doi.org/10.1016/j.cej.2014.05.132.

33. M. A. Gonzalez, I. Pavlovic and C. Barriga, Chem. Eng. J., 269 (2015) 221. doi.org/10.1016/j.cej.2015.01.094.

34. R. Shan, L. Yan, K. Yang, Y. Hao and B. Du, J. Hazard. Mater., 299 (2015) 42. doi.org/10.1016/j.jhazmat.2015.06.003.

35. O. Rahmanian, M. H. Maleki and M. Dinari, J. Phys. Chem. Solids, 110 (2017) 195.

doi.org/10.1016/j.jpcs.2017.06.018.

36. O. Rahmanian, M. Dinari and M. K. Abdolmaleki, Appl. Surf. Sci., 428 (2018) 272.

doi.org/10.1016/j.apsusc.2017.09.152.
37. M. S. Mostafa and A. B. Al-Sayed, Energy Sources Part A, 41 (2018) 2257. doi.org/10.1080/15567036.2018.1555629.

38. X. Zhang, Y. Dou, C. Gao, C. He, J. Gao, S. Zhao and L. Deng, Sci. Total Environ., 685 (2019) 951. doi.org/10.1016/j.scitotenv.2019.06.228.

39. M. Dinari, A. Haghighi and P. Asadi, Appl. Clay Sci., 170 (2019) 21. doi.org/10.1016/j.clay.2019.01.007.

40. M. Chen, P. Wu, Z. Huang, J. Liu, Y. Li, N. Zhu, Z. Dang and Y. Bi, J. Environ. Manage., 246 (2019) 164. doi.org/10.1016/j.jenvman.2019.06.002.

41. Y. Tan, X. Yin, C. Wang, H. Sun, A. Ma, G. Zhang and N. Wang, Environ. Pollut. Bioavailab., 31 (2019) 189. doi.org/10.1016/j.jcis.2018.10.066.

42. M. Shi, Z. Zhao, Y. Song, M. Xu, J. Li and L. Yao, Appl. Clay Sci., 187 (2020) 105482. doi.org/10.1016/j.clay.2020.105482. 